\title{
VIOLÊNCIA, LETRAMENTO LITERÁRIO E FORMAÇÃO LEITORA: DESAFIOS À ATUAÇÃO DOCENTE
}

\author{
VIOLENCE, LITERARY LETTERING AND READING TRAINING: CHALLENGES \\ TEACHING PERFORMANCE
}

Luana Teixeira Porto 1

\begin{abstract}
RESUMO
O objetivo deste artigo é propor uma discussão sobre leitura literária com vistas ao letramento e à formação leitora em um contexto em que a leitura crítica sobre temas caros à sociedade, em especial 0 tema da violência, pode ser caminha para umam formação mais cr'tiica e cidadã. Para isso, adotam-se como metodologia para a proposição e práticas letras estudos de Franco Júnior (2015) e Rösing (2016). Ao desenvolver um estudo crítico sobre as metodologias de abordagem do texto literário, defende-se a necessidade de tratar o texto literário como um objeto estético e ético e não como recurso pedagógico ou pretexto para abordagem de conteúdos disciplinares. Além disso, propõe-se uma formação leitora que possibilite a experiência estética e o posicionamento crítico sobre os textos, procurando especialmente analisar linguagem literária em sua relação com outros textos, de natureza literária ou não, o que aproxima a proposta de prática leitora voltada a inter-relação entre linguagens prevista nos materiais norteadores para o Ensino Médio, como a BNCC e os PCN's.
\end{abstract}

PALAVRAS-CHAVES: violência; letramento literário; Ensino Médio; leitura.

\section{ABSTRACT}

The purpose of this article is to propose a discussion on literary reading with a view to literacy and reading training. For this, the methodology adopted by Franco Júnior (2015) and Rösing (2016) is the methodology for proposing and practicing letters. When developing a critical study on the methodologies of approach to the literary text, the need to treat the literary text as an aesthetic and ethical object is defended and not as a pedagogical resource or pretext for approaching disciplinary contents. In addition, we propose a reading training that enables the aesthetic experience and the critical positioning on the texts, especially seeking to analyze literary language in its relationship with other texts, whether literary in nature or not, which brings the proposed reading practice closer to interrelationship between languages foreseen in the guiding materials for High School, such as BNCC and PCN's.

KEYWORDS: violence; literacy lettering; High school; reading.

\section{INTRODUÇÃO}

Em um contexto social líquido (na perspectiva de Bauman) e sombrio (na perspectiva de Adorno), marcado por violências sociais, físicas, verbais, institucionais, econômicas e por deficiências no campo educacional brasileiro, torna-se relevante discutir a formação de leitor,

${ }^{1}$ Doutora em Letras e professora dos cursos de Metrado e Doutorado em Educação da Universidade Regional Integrada do Alto Uruguai e das Missões. Email: luanatporto@gmail.com 
que, mais do que ler o mundo, precisa ser competente para ler textos. Em especial, temos que discutir a função da arte em um cenário em que ela pode ser um contraponto à barbárie que parece se impor coletivamente contra vontades individuais e consciências coletivas. Nesse sentido, acredita-se no papel da literatura como objeto estético e ético capaz de despertar não só prazer em ler, mas também estimular comportamentos socialmente relevantes, como o exercício da alteridade e da não-violência tal como propõe Ginzburg (2012).

Dessa forma, considerando a urgência de uma formação cidadã e de uma educação em direitos humanos, que envolve esses tipos de posturas, e a sua relação com o letramento literário como competência a ser revelada entre os estudantes da Educação Básica, este trabalho discute problematizações acerca das relações entre formação do leitor e literatura no Ensino Médio, tendo em vista especialmente a necessidade de tornar e leitura do texto literário uma atividade não apenas de avaliação estética, mas também de desenvolvimento de um senso crítico amparado em posicionamentos éticos e sociais capazes de estimular a construção de uma experiência social baseada na cultura da paz e na atenção a direitos humanos fundamentais. Para tanto, o estudo apresenta uma proposta de prática leitora amparada em três eixos: letramento literário, cultura da não-violência e educação em direitos humanos.

O objetivo deste artigo é propor uma discussão sobre prática leitora que inter-relacione leitura literária com vistas ao letramento e à formação para a cultura de paz e a educação em direitos humanos por meio de atividades que envolvam textos literários para leitores adolescentes do Ensino Médio. Tal proposta ampara-se em dados alarmantes sobre a violência no país e denúncias de violações constantes de direitos humanos em vários setores da sociedade.

Como exemplo, basta citar que o Atlas da Violência 2019 apontou que: de 2017 a 2007, houve aumento de $37,6 \%$ no número de assassinatos de jovens no Brasil; mais de $75 \%$ das vítimas de homicídios forma pessoas negras; de 2016 a 2017, aumentou em 127\% a violência contra pessoas pertencentes à comunidade LGBTI+; de 2017 a 2007, houve aumento de homicídios de mulheres, sendo que a taxa de morte das mulheres negras cresceu 29,9\% e a de brancas, 4,5\%. (IPEA, 2019). Tais dados apontam para um cenário desolador da violência no Brasil, alimentado pela histórica desigualdade social e ausência de polícias públicas efetivas e eficazes de combate a diferentes formas de violência no país, o que se intensifica quanto são considerados outros contextos, como o do sistema carcerário brasileiro. Neste há seguidamente denúncias de violência física e tortura contra presidiários, falta de água e comida, além de condições sanitárias e de acomodação adequadas, tal como é possível verificar em notícias de 
jornais ${ }^{2}$ e sites do mundo jurídico que publicam resultados de estudos sobre violência carcerária 3 .

Essas situações acenam para a necessidade de se pensar na formação educacional apara a cultura da não-violência e a urgência de uma educação voltada aos Direitos humanos como forma de vivência social mais harmoniosa e lealmente mais segura. Isso porque, quando se trata de Direitos humanos, é preciso saber que eles estão há mais de setenta anos indicados na Declaração Universal dos Direitos Humanos, ratificada por vários países, entre os quais o Brasil. No entanto, o que se nota é uma dificuldade de direitos associados à dignidade da pessoa humana, que não deve ser exposta a violência, serem pouco garantidos, como indica Avelar:

\footnotetext{
Passado o seu sexagésimo aniversário, a Declaração Universal dos Direitos Humanos continua sendo pisoteada, talvez hoje mais do que nunca. Poucos documentos combinam tanto prestígio e tanta irrelevância. Poucos são tão amplamente reconhecidos e, ao mesmo tempo, tão desrespeitados. (2011, p. 235).
}

Para isso, adotam-se como metodologia para a proposição e discussão de práticas leitoras estudos de Franco Júnior (2015), Petit (2009) e Rösing (2016). Ao desenvolver um estudo crítico sobre as metodologias de abordagem do texto literário, defende-se a necessidade de tratar 0 texto literário como um objeto estético e ético e não como recurso pedagógico ou pretexto para abordagem de conteúdos disciplinares. Além disso, propõe-se uma formação leitora que possibilite a experiência estética e o posicionamento crítico sobre os textos, procurando especialmente analisar linguagem literária em sua relação com outros textos, de natureza literária ou não, o que aproxima a proposta de prática leitora voltada a inter-relação entre linguagens prevista nos materiais norteadores para o Ensino Médio, como a BNCC e os PCN's.

\section{LEITURA E LETRAMENTO LITERÁRIO}

A despeito do espaço reduzido dado à literatura na formação escolar - dada a não exigência em documentos oficiais de uma disciplina específica de formação em literatura -, não é possível

2 Notícia que aponta violência na prisão em Minas Gerais pode ser verificada em: https://www.em.com.br/app/noticia/gerais/2020/06/25/interna_gerais,1159986/estudo-expoe-violencianos-presidios-ato-cobra-acao-do-governo.shtml . Acesso em: 30 jun. 2020.

${ }^{3}$ Ver, por exemplo: https://jus.com.br/artigos/68775/sistema-carcerario-historia-de-violencia-nas-prisoes. Acesso em: 10 abr. 2020. 
negar a contribuição da literatura para a formação humana e seu papel essencial na formação de sujeito comprometidos com a sensibilidade, a empatia, a valorização do outro e, sobretudo, a interpretação da sociedade. Ler literatura, sobretudo para aqueles que conseguem significar a prosa e o verso que não se amoldam a linguagem do cotidiano, implica construir uma visão de mundo ampliada sobre si mesmo e o semelhante, uma leitura que nem sempre é possibilitada pelo contato com textos de natureza técnica ou informativa.

Dessa forma, compactua-se com a visão de Maurício Silva segundo a qual a leitura do texto literário pode propiciar o desenvolvimento de habilidades que tornam o leitor menos passivo e leniente diante de situações-problema que precisam de posicionamento dirigido, postura ética, comportamento solidário e socialmente correto. Para o autor:

\begin{abstract}
Lidar com a literatura é, portanto, uma maneira de compreender melhor e mais a fundo uma espécie de instrumento capaz de desautomatizar nossa percepção do cotidiano, agindo no sentido contrário à padronização de nossa apreensão da realidade; de desenvolver nossa sensibilidade e inteligência, habilitando-as plenamente para uma leitura mais abrangente do mundo; de despertar nossa capacidade de indignação, criando em cada um de nós uma consciência crítica da realidade circundante; de alicerçar nossa conduta ética no trato social, a fim de aperfeiçoar nossas inter-relações humanas; e de desenvolver nossa capacidade de compreensão e absorção da atividade estética, a partir de uma prática hermenêutica consistente. (2013, p. 308)
\end{abstract}

Essa prática de leitura mais consistente do texto literário pressupõe uma relação ativa entre texto e leitor, que não pode ficar preso a atividades de decodificação do verbum nem à compreensão da obra por meio da sua "classificação" em escolas literárias, como infelizmente grande parte das escolas ainda propõe e historicamente tem sido proporcionado aos estudantes em aulas de literatura no Ensino Médio. Ler literatura, compreendê-la e interpretá-la requer habilidades outras que não se restringem ao ensino de período literários e decorebas de traços que mais servem para acertar questões dos tradicionais vestibulares como que significar os textos, elaborando sentido para o que se lê.

Nesse sentido, vários alertas de diferentes pesquisadores têm sido registrados em entrevistas, artigos, livros com o intuito de apontar caminhos não adequados para a abordagem do texto literário na sala de aula. Tania Rösing (2010) é uma das estudiosas que se posiciona sobre isso ao tratar de como a universidade tem apresentado literatura e autores, sobretudo autores novos da literatura contemporânea. Para ela, a universidade apresenta "ranços" que fazem com que alguns autores e obras sejam apresentados e outros não e ainda permite que se 
formem professores com preparação para ensino voltado à periodização literária quando deveria haver enfoque para o envolvimento do leitor com o texto, o que permite a formação do leitor e a produção de sentido sobre o que se lê.

Rösing (2010) também aponta para a produtividade da leitura literária na perspectiva de pôr em relação diferentes textos na simples busca pela compreensão do que uma obra literária diz, possibilitando assim leituras cruzadas e a compreensão do hipertexto e do hipotexto:

\begin{abstract}
Há coisas que entram na academia e coisas que não entram na academia. Por exemplo, nós estamos trabalhando com um ensino de literatura que parte do envolvimento com a obra. É aí que se faz a formação do leitor. $O$ que a academia faz é trabalhar com periodização. Ela trabalha o arcadismo, o romantismo, o simbolismo, o pré-modernismo, o modernismo, tudo que não se entende como um processo complexo. Porque a literatura traz elementos da história, ela é contextualizada, evidentemente. E há os elementos que são baseados no real. Então temos história e literatura, sociologia e literatura. Nós não podemos trabalhar de forma fragmentada. Agora as pessoas dizem que com a internet nós precisamos trabalhar a literatura a partir do hipertexto. Mas ele sempre existiu! 0 que é o hipertexto? Você está lendo um livro e por não ter uma informação você vai buscar em uma enciclopédia, vai buscar um dicionário. São informações sobre palavra ou sobre a biografia do autor. Um texto mais um dicionário mais uma enciclopédia. Isso é hipertexto. (2010, p. 7-8)
\end{abstract}

O que Rösing (2010) aponta leva a uma consideração importante acerca da leitura, que é a possibilidade de a leitura condicionar habilidades mais amplo, como a de letramento, em especial o letramento literário. Em primeiro lugar, quando se trata dessa expressão letramento, é preciso registrar que não pode ser confundido com alfabetização, como já destacou Magda Soares ao abordar a introdução do termo nos estudos no Brasil: "'é em meados dos anos de 1980 que se dá, simultaneamente, a invenção do letramento no Brasil, do illettrisme, na França, da literacia, em Portugal, para nomear fenômenos distintos daquele denominado alfabetização, alphabétisation" (SOARES, 2014, p. 6). Para a autora, o letramento implica habilidades mais amplas associadas ao uso da língua, como a função social da leitura e da escrita, o uso da língua para o estabelecimento de relações de criticidade com o que se lê e produz e, assim, admite-se a possibilidade de o sujeito ser alfabetizado e não ser letrado. Para Magda Soares (2014), "Letrar é mais que alfabetizar, é ensinar a ler e escrever dentro de um contexto onde a escrita e a leitura tenham sentido e façam parte da vida do aluno." Todavia, o letramento requer alfabetização, ou seja, não há duas habilidades dissociadas: "o letramento, o qual garantirá uma verdadeira transformação do indivíduo, não pode vir desacompanhado da alfabetização. Isto é, do aprendizado efetivo da leitura e da escrita. Cabe ressaltar que utilizamos a palavra 
"(des)acompanhado", que coloca os dois aspectos como mutuamente importantes e não mutuamente excludentes." (MOTA, 2007, p.120)

Em segundo lugar, nessa significação mais ampla sobre uso da palavra, é fundamental compreender que "Os estudos do letramento, por outro lado, partem de uma concepção de leitura e de escrita como práticas discursivas, com múltiplas funções e inseparáveis dos contextos em que se desenvolvem." (KLEIMAM, 2007, p. 2). Em outras palavras, a concepção de letramento aponta a importância de saber fazer uso do ler e do escrever, saber responder às exigências de leitura e de escrita que a sociedade continuamente faz, e, por isso, a condição para a uma leitura com vistas ao letramento deve envolver o contexto de produção e circulação dos textos. No caso dos textos literários, isso acarreta a necessidade de se compreender a obra literária como um produto cultural, inscrito em um cenário de mercado editorial, tendência e linguagem literária, gêneros de produção específicos, visões de mundo do autor e de seus leitores. Logo, tem-se o "letramento literário", que junto com os demais tipos de letramento político, informacional, digital, semiótico, social - constitui os multiletramentos. Conforme explica Kleiman (2007), o termo multiletramentos é originado do Grupo de Nova Londres:

\begin{abstract}
No texto de declaração de princípios dos pesquisadores do grupo, de orientação pedagógica, os autores advogam por uma concepção de letramento muito mais ampla do que aquela que em geral embasa o trabalho escolar, e propõem o ensino de multiletramentos, isto é, a inclusão no currículo de todas as formas de representar significados dos diferentes sistemas semióticos - linguístico, visual, sonoro ou auditivo, espacial e gestual - inter-relacionados no texto multimodal contemporâneo. (p. 81)
\end{abstract}

Considerando-se a necessidade de um currículo que permita ao aluno desenvolver todas essas habilidades, é preciso apontar alguns desafios que se mostram latentes no cenário atual da educação básica no Brasil. Um cenário em que é necessário fazer com que a leitura seja meio para reflexão e problematização de situações que envolvem o sujeito, entre elas a violência e medidas para seu enfrentamento.

A escolha pela abordagem da violência se dá por várias razões que envolve tanto aspectos culturais, quanto históricos, e sociais assim como educacionais: a) a violência como elemento constitutivo da sociedade brasileira (GINZBURG, 2012); b) a violência apresentada como espetáculo, sobretudo em produções culturais da televisão e do cinema que exploram a temática como objeto de consumo e não de rechaça ou de tema a ser refletido criticamente; c) a violência crescente no cenário brasileiro em suas múltiplas formas, social, urbana, policial, de gênero etc; d) a violência como tema transversal cuja abordagem permite aos sujeitos construir um olhar 
interdisciplinar e compreender sociedade, cultura, história como espaços de discussão em que a viole deve ser tema obrigatório.

Tendo-se em vista que se defende a perspectiva segundo a qual a violência deveria ser discutida na escola, propõe-se pensar em duas questões, as quais levam à discussão sobre desafios à prática docente com foco em letramento e abordagem do tema da violência: Sendo a realidade social marcada por violência, muitas vezes apresentada como espetáculo a ser consumido em diversas produções culturais, é possível combater esse cenário por meio da leitura? Como explorar a arte literária em um cenário em que ela pode ser um contraponto à barbárie que parece se impor coletivamente contra vontades individuais e consciências coletivas? Dessa forma, a próxima seção deste artigo aponta desafios e possibilidades de se pensar o desenvolvimento do letramento literário e seu enfoque sobre leitura que permite compreender e combater prática de violência.

\section{VIOLÊNCIA E LETRAMENTO LITERÁRIO: DESAFIOS À PRÁTICA DOCENTE}

Ao se debater sobre a abordagem da violência e como esse tema pode incitar práticas que visão ao letramento literário, faz-se uma lista de desafios, que serão apresentados em sequência na forma de itens de reflexão.

1. Formar professores efetivamente leitores. Não se pode conceber a prática de leitura mediada por professores que não tenham o hábito nem a prática de leitura nem repertório adequado de leitura. Como destaca Berenblum (2006, p. 28), não basta apenas um professor que leia, é necessário que o professor seja capacitado para fazer com que os alunos gostem de ler e sejam proficientes nessa competência:

Não se trata de um professor que apenas "leia", mas de um professor que leia com competência e autonomia, capaz não apenas de incentivar seus alunos, mas de mostrar-lhes as sutilezas e entrelinhas dos textos, em especial dos textos escritos.

2. Revisão de currículos de licenciatura. Não se pode esperar de um professor que ele desenvolva práticas leitoras consistentes se ele não tiver aprendido a fazê-las enquanto estudante de licenciatura. Esse curso deve possibilitar ao futuro docente concepções teóricas e metodológicas sobre práticas de leitura e letramento literário. Isso implica que o professor formado tenha clareza sobre qual concepção de texto e de leitura vai adotar e que metodologias pode explorar para mediar as ações de formação do leitor mirim e adolescente. Não é admissível em um professor que deva trabalhar com linguagens em qualquer nivel de ensino não tenha 
noção clara de texto, intertexto, letramento, multiletramentos em um contexto em que isso já é apontado como elemento essencial para a formação na educação Básica. Tal prerrogativa deve envolver, sobretudo, cursos de Pedagogia e Letras, mas não só, uma vez que o ensino de leitura deve ser tarefa de todos os professores.

3. Desmitificação da leitura literária como atividade desinteressante e improdutiva. Em um contexto social marcado pelo imediatismo e pelo consumo, a literatura reflexiva tem preferido espaço para leituras mais leves, curtas ou superficiais. Assim, não causa espanto o fato de um leitor preferir uma tirinha de Armandinho a um romance de Machado de Assis ou uma canção do sertanejo universitário a uma canção de protesto da época da Ditadura Militar brasileira. Isso não significa, em hipótese alguma, desvalorizar tirinhas ou canções populares do sertanejo universitário, que devem ser objeto de apreciação e reflexão na sala de aula, mas de ressaltar que textos mais complexos e elaborados precisam ser lidos, entendidos e dignificados pelos estudantes. Apresentar literatura de grandes clássicos e bem elaborada é medida que se impõe, oferecer literatura de massa é importante, mas não pode ser a única fonte de leitura dos estudantes, pois, de acordo com Bosi, há um gosto por textos de linguagem simples e leitura imediata, superficial:

O indivíduo-massa, a personalidade construída a partir da generalização da mercadoria, quando entre no universo da escrita (o que é um fenômeno deste século), o faz com vistas ao seu destinatário, que é o leitor-massa, faminto de uma literatura que seja especular e espetacular. Autor e leitor perseguem a representação do show da vida, incrementado e amplificado. Autor-massa e leitor-massa buscam a projeção direta do prazer ou do terror, do paraíso do consumo ou do inferno do crime _ uma literatura transparente, no limite sem mediações, uma literatura de efeitos imediatos e especiais, que se equipare ao cinema documentário, ao jornal televisivo, à reportagem ao vivo (...) o filme, imagem em movimento, teria tornado supérflua, para não dizer indigesta, a descrição miúda (...) Uma cena de um minuto supriria, no cinema, o que o romancista levou mais de uma dezena de páginas para compor e comunicar ao seu leitor (BOSI, 1994, p.109-110).

4. Inserção de tecnologias associadas a práticas de leitura e de letramento literário. A leitura pode ser realizada por meio de um dispositivo digital. O estudante pode ler um livro impresso ou um digital, ler um jornal impresso ou uma notícia em um site. Não é o meio de acesso ao texto que vai indicar se a leitura é ou não produtiva e, sim, a qualidade das práticas de leitura e letramento ofertadas ao aluno-leitor. O letramento, em suas múltiplas facetas, prevê relações entre textos e compreensão de textos que nem sempre são associados a mecanismos de divulgação não impressa e, atualmente, há muitas possibilidades de desenvolvimetno de propsotas de leitura pro meio de recursos tecnológicos digitais, objetos de aprendizagem que se espalham em redes da internet, por exemplo. Logo, corrobora-se a visão de Míriam Zafalon: 
Para uma mudança de parâmetros que privilegiem um ensino da literatura com qualidade, os novos recursos comunicacionais podem ser compreendidos como geradores de uma nova mentalidade educacional, permitindo que a aceleração tecnológica venha compor um arsenal de instrumentos para desmistificar o ensino da literatura como atividade de natureza senil, hermética e desinteressante. (ZAFALON, 2001, p. 24)

5. Adoção de leitura literária associada a leitura de textos produzidos em diversas linguagens. A inter-relação de texto precisa ser reconhecida pelo aluno leitor, que poderá pôr em relação uma crônica de Moacyr Scliar e uma charge de um jornal, ou um romance de Machado de Assis e um telenovela, ou uma leitura de um conto de Ana Paula Maia e um documentário da TV a cabo. O olhar comparatista potencializa um trabalho na lógica do incentivo aos multiletramentos na escola, pois

os multiletramentos envolvem 0 abandono do discurso que preconiza, segundo Chartier (2011, p.59) "a leitura lenta, atenta, exaustiva de um corpus fechado, de textos escolhidos com cuidado e relidos de geração em geração", que imperou, segundo 0 autor, até a década de 1960 na França e até bem mais recentemente no Brasil, onde podemos talvez remontar a emergência de um discurso alternativo à década de publicação dos PCN , no final dos anos 1990. (KLEIMAN, 2007, p. 81)

6. Formação intercultural e em Direitos Humanos para professores. A atuação docente hoje não se revela apenas em habilidades e competências necessárias à construção de conhecimento específico de sua área, porque o professor precisa ser leitor do mundo, leitura da cultura, da sociedade, de seu tempo presente e passado. Isso requer que formação em nível superior e formação continuada ampliem temas até então tradicionais que tratam de metodologias, epistemologias, teorias e discutam temas transversais que possam ampliar os horizontes culturais dos professores. Oferecer ao professor debate com pensadores de outas áreas e estimular a formação continuada por meio da pesquisa é u desafio que se apresenta, em especial em relação a temas mais sensíveis, como 0 dos Direitos Humanos, normalmente associado a Ciências Sociais, mas não limitado a esse campo.

7. Debate sobre violência dentro e fora da escola. A violência no contexto brasileiro "tem um papel constitutivo, uma hipótese de trabalho produtiva consiste em partir da premissa de que a violência tem um papel fundamental para a literatura brasileira". (GINZBURG, 2012, p. 244). Logo, é preciso que essa compreensão chegue a um número cada vez mais amplo de pessoas 
que fazem parte de uma comunidade escolar, pois tal reflexão pode ajudar a discussão sobre formas de enfrentamento, o que pode ser feito por meio de atividades de leitura literária:

0 acesso a questionamentos sobre a violência por meio da literatura permite romper com a apatia, o torpor, de um modo importante. Textos literários podem motivar empatia por parte do leitor para situações importantes em termos éticos. (GINZBURG, 2012, p. 24)

8. Debate sobre cultura da paz dentro e fora da escola. A escola, como um espaço social de interação e de (trans)formação pode contribuir para a conscientização de toda a comunidade da necessidade de se instituir uma cultura de paz. 0 processo educativo determina que a escola também seja agente de reflexão sobre a cultura de paz, e o projeto de uma cultura de paz pode ser um objetivo da proposta pedagógica de cada educandário comprometido com experiências de vida e de formação que possam oportunizar à comunidade a escolha por um ambiente sadio, dentro e fora dos muros da escola. Dessa forma, envolver a comunidade escolar nesse debate implica compreender que cabe a crianças, jovens, adultos e senis a postura coletiva em prol de uma sociedade mais harmônica, de uma relação social com menos discurso de ódio ou postura bélica. Isso porque:

Construir uma cultura da paz envolve dotar as crianças e os adultos de uma compreensão dos princípios e respeito pela liberdade, justiça, democracia, direitos humanos, tolerância, igualdade e solidariedade. Implica uma rejeição, individual e coletiva, da violência que tem sido parte integrante de qualquer sociedade, em seus mais variados contextos. A cultura da paz pode ser uma resposta a diversos tratados, mas tem de procurar soluções que advenham de dentro da (s) sociedade (s) e não impostas do exterior. (...) Uma cultura de paz implica no esforço para modificar o pensamento e a ação das pessoas no sentido de promover a paz. Falar de violência e de como ela nos assola, deixa de ser a temática principal. Não que ela vá ser esquecida ou abafada; ela pertence ao nosso dia a dia e temos consciência disto. Porém, o sentido do discurso, a ideologia que o alimenta, precisa impregná-lo de palavras e conceitos que anunciem os valores humanos que decantam a paz, que Ihe proclamam e promovem." (DUPRET, 2002, p. 91)

\section{CONSIDERAÇÕES FINAIS}

O fechamento deste texto aponta algumas observações que merecem registro e que não forma apresentadas ainda. Uma delas é a de que os desafio elencados na seção anterior são parte de uma reflexão em construção decorrente de projeto de pesquisa que envolve Linguagens, literatura e ensino. Logo, ainda serão desdobradas e ampliadas em termos de 
argumentação e teorização, com vistas a uma proposição de cunho prático para práticas leitoras em sala de aula.

A segunda associa-se à ideia de que é necessário tratar o texto literário como um objeto estético e ético e não como recurso pedagógico ou pretexto para abordagem de conteúdos disciplinares. Tal perspectiva amplia-se na medida em que também se reconhece ser oportuno criar proposição de formação leitora que possibilite a experiência estética e o posicionamento crítico sobre os textos, procurando especialmente analisar linguagem literária em sua relação com outros textos, de natureza literária ou não, o que aproxima a proposta de prática leitora voltada a inter-relação entre linguagens prevista nos materiais norteadores para o Ensino Médio, como a BNCC e os PCN's, o que levará ao letraemtno literário.

Por fim, ressalta-se que práticas leitoras podem assumir um papel crucial na formação do sujeito-aluno-cidadão ao privilegiar 0 ato de tensionar a violência e não a banalizar na construção de uma sociedade amparada na cultura de paz, tal como se revela oportuno no contexto atual brasileiro.

\section{REFERÊNCIAS}

ATLAS DA violência 2019. Instituto de Pesquisa Econômica Aplicada; Fórum Brasileiro de Segurança Pública (Orgs,). Brasília: Rio de Janeiro: São Paulo: Instituto de Pesquisa Econômica Aplicada; Fórum Brasileiro de Segurança Pública, 2019. Disponível em: < https://www.ipea.gov.br/atlasviolencia/download/19/atlas-da-violencia-2019>. Acesso em: 20 abr. 2020.

AVELAR, Idelber. Vida nua e direitos humanos na era da guerra sem fim. In: Figuras da violência: ensaios sobre narrativa, ética e música popular. Belo Horizonte: Ed. UFMG, 2011. p. 235-244.

BERENBLUM, Andréa. Por uma política de formação de leitores. Brasília: Ministério da Educação, Secretaria de Educação Básica, 2006.

DUPRET, Leila. Cultura de paz e ações sócio-educativas: desafios para a escola contemporânea. Psicol. Esc. Educ. (Impr.), v.6, n.1, p. 91-96, Campinas, jun. 2002.

GINZBURG, Jaime. Crítica em Tempos de Violência. São Paulo: Editora da Universidade de São Paulo/Fapesp, 2012.

KLEIMAN, Angela B. Os significados do letramento: uma nova perspectiva sobre a prática social da escrita. Campinas, SP: Mercado das Letras, 1995. São Paulo, Contexto, 2007. 
MOTA, Márcia Elia da. Algumas considerações sobre o letramento e o desenvolvimento metalingüístico e suas implicações educacionais. Estudos e pesquisas em psicologia, UERJ, RJ, n. 3, p. 118-130, 2007.

RÖSING, Tania. Entrevista realizada por Fabio Maleronka Ferron e Sergio Cohn no dia 17 de abril de 2010, em São Paulo. Disponível em: <

http://rubi.casaruibarbosa.gov.br/bitstream/20.500.11997/7195/93/T\%C3\%A2nia\%20R\%C3\%B6s ing\%20-\%20entrevista\%2017.04.2010.pdf>. Acesso em: 14 out. 2020.

SILVA, Mauricio. Ensino de literatura em tempos de transformação (a literatura e seus diálogos). Revista Brasileira de Literatura Comparada, São Paulo, n.22, 2013, p. 307-325. Disponível em: < http://www.abralic.org.br/revista/2013/22/170/download>. Acesso em: 20 maio 2014.

SOARES, Magda. Letramento: um tema em três gêneros. 3. ed. Belo Horizonte: Autêntica, 2009.

ZAFALON, Míriam. Aulas de literatura e novas tecnologias: a TV multimídia como mediação para a fruição literária. 2011. Disponível em:

http://dspace.c3sl.ufpr.br/dspace/bitstream/handle/1884/33576/MIRIAM\%20ZAFALON.pdf?seque nce=1. Acesso em: 12 mai. 2014. 